\title{
Quality analysis of discharge instruction among 602 hospitalized patients in China: a multicenter, cross-sectional study
}

\author{
Miao-miao Yang, Wei Liang, Hui Hua Zhao* and Ying Zhang
}

\begin{abstract}
Background: The aim of this study was to understand the quality of discharge guidance for patients with chronic diseases, to clarify the gap between patient needs and the content of discharge guidance, and to provide a reference for health education and clinical path management of patients with chronic diseases in the future.

Methods: A total of 602 inpatients with stroke, coronary heart disease, cancer, chronic obstructive pulmonary disease and diabetes from the chronic disease-related departments of 7 tertiary general hospitals in China were selected by convenience sampling. Measures included a demographic questionnaire and the Quality of Discharged Teaching Scale(QDTS). Descriptive analysis ANOVA and paired t-test were completed by SPSS 22.0 software.

Results: The overall average score of QDTS in this survey was $155.79 \pm 23.29$. The total score of QDTS in chronic obstructive pulmonary disease was lower than coronary heart disease $(P<0.001)$ and cancer $(P=0.02)$. While coronary heart disease was higher than stroke $(P=0.01)$ and diabetes $(P=0.01)$. And the scores of patients on discharge guidance skills and effects were higher than 8.50 .

Conclusions: The level of the patients' perception of quality of discharge insrtuction is middle to high. Managers should understand the characteristics of various departments, give corresponding guidance and help, and clinical nurses should understand the characteristics of ward patients and pay more attention to individual guidance.
\end{abstract}

Keywords: Chronic disease, Discharge, Quality, Education

\section{Background}

The prevalence of chronic diseases is high and the course of disease is long and protracted [1]. The rise in chronic illness is shifting the role of the nurse to that of facilitator in the patient's self-management process. The increase in availability of personal disease monitoring tools such as hand-held, self-monitoring blood glucose systems [2], and a focus on patients as consumers of health care is moving expectations around management of chronic conditions away from physicians to the patients themselves. Studies have found that providing

\footnotetext{
* Correspondence: zhh20417@126.com

Department of nursing, Zhongshan Hospital Fudan University, 180 Fenglin Road, Xuhui District, Shanghai 200032, China
}

patients with personalized health information and reminders can improve compliance with guidelines, health status and patient satisfaction $[3,4]$.

However, the provision of discharge education is challenging. In a population-based patient satisfaction survey, $11 \%$ of patients reported that they had not received adequate information about their diagnosis and treatment plan at the time of discharge [5]. Nearly 1 in 5 patients experiences an adverse event during this transition, with a third of these being likely preventable [6]. Discharge guidance is a form of education and communication designed by nurses and other medical personnel to provide patients and/or caregivers with important information about medical care [7]. As an

(C) The Author(s). 2020 Open Access This article is licensed under a Creative Commons Attribution 4.0 International License, which permits use, sharing, adaptation, distribution and reproduction in any medium or format, as long as you give appropriate credit to the original author(s) and the source, provide a link to the Creative Commons licence, and indicate if changes were made. The images or other third party material in this article are included in the article's Creative Commons licence, unless indicated otherwise in a credit line to the material. If material is not included in the article's Creative Commons licence and your intended use is not permitted by statutory regulation or exceeds the permitted use, you will need to obtain permission directly from the copyright holder. To view a copy of this licence, visit http://creativecommons.org/licenses/by/4.0/ The Creative Commons Public Domain Dedication waiver (http://creativecommons.org/publicdomain/zero/1.0/) applies to the data made available in this article, unless otherwise stated in a credit line to the data. 
important part of holistic nursing, discharge guidance is the premise and guarantee for patients to continue to comply with the doctor and recover after discharge [8]. After discharge, the care responsibility of patients is transferred from medical service providers to patients and caregivers, so comprehensive discharge instructions are necessary to achieve the safely transition between hospital and home [9]. Therefore, the purpose of this study is to understand the quality of discharge guidance for patients with chronic diseases, to clarify the gap between patient needs and the content of discharge guidance, and to provide a reference for health education and clinical path management of patients with chronic diseases in the future.

\section{Methods}

\section{Study design and sample}

A total of 602 inpatients with stroke, coronary heart disease(CHD), cancer, chronic obstructive pulmonary disease(COPD) and diabetes from the chronic diseaserelated departments of 7 tertiary general hospitals in Shanghai were selected by convenience sampling between August and October 2018. The inclusion criteria for patients were: age $\geq 18$ years, met the diagnostic criteria for chronic diseases, had certain literacy skills, participated voluntarily and gave signed informed consent. Patients with a poor physical condition, such as severe impairment of vision and/or hearing, or who were unable to complete the questionnaire, were excluded. The study was approved by the Hospital Ethics Committee.

\section{Instruments}

\section{Demographic questionnaire}

The questionnaire designed for this study included: patient gender, age, marital status, living arrangement, living environment, educational status, employment, income, medical diagnoses, disease course, length of stay, hospitalization frequency, knowledge of disease, and take medicine regularly. The questionnaire is included as additional Supplementary Material.

\section{Quality of discharged teaching scale (QDTS)}

QDTS was developed by Weiss et al. [10] and has been widely used in spinal cord injury, stroke, and orthopedic patients $[11,12]$. Translation of the QTDS into the Chinese version was done with the process of translation, back-translation, culture adaption, expert consultation and pre-test, and then chose 167 coronary heart disease from a tertiary general hospital in Wuhan to test the reliability and validity of the Chinese version scale [13]. The Cronbach's alpha of the whole scale was 0.92, and those for the subscales ranged from $0.88-0.94$. The S-CVI/
Ave value was 0.98 and all of the computed I-CVI values were greater than 0.80 . The scale consisted of 24 items using a $0-10$-point Likert scale in 3 subscales: teaching contents that patients thought they needed (6 items), teaching contents that patients received (6 items), and teaching skills and effectiveness (12 items). The total scale score is calculated by adding the content needed and the content received subscale scores, with higher scores indicating better quality. The total scale can be considered both a measure of receiver characteristics of the nursing process and the outcome of the nursing process of discharge teaching. The scale has been authorized by the author.

\section{Data collection procedures}

Trained study research assistants completed informed consent procedures and arranged for completion of the sociodemographic information and QDTS on the day of patient discharge. All questionnaires were collected on site by the research assistants after completion. So, there were no missing items from the study. A total of 620 questionnaires were sent out and 602 valid questionnaires were analysed.

\section{Data analysis}

Continuous variables were reported as mean standard \pm deviation (SD). While categorical variables were expressed as frequency, percentage. ANOVA and paired $\mathrm{t}$-test were used for comparison between groups. All data analyses were performed by SPSS 22.0 statistical software.

\section{Results}

Demographic and clinical characteristics of the participants

Of all the 602 patients, $62.1 \%$ were male and $37.9 \%$ were female with ranging ages from 18 to 95 years (mean: $62.21 \pm 14.37$ years). The average length of hospital stay was $11.55 \pm 16.23$ days. Participants' demographic characteristics are shown in Table 1.

\section{The quality of discharge teaching perceived by chronic disease patients}

The overall average score of QDTS in this survey was $155.79 \pm 23.29$. And the total score of QDTS and the scores of each dimension of patients with different kinds of diseases are compared in Table 2. Further comparison of the total score of QDTS by pairwise comparison shows that COPD was lower than CHD $(P<0.001)$ and cancer $(P=0.02)$. While CHD was higher than stroke $(P=0.01)$ and diabetes $(P=0.01)$. There were no statistically significant differences between COPD and stroke 
Table 1 Characteristics of participants $(n=602)$, China, 2018

\begin{tabular}{|c|c|c|c|c|}
\hline & Characteristics & Mean (SD) & Frequency(n) & Percentage(\%) \\
\hline \multirow[t]{2}{*}{ Gender } & Male & & 374 & 62.1 \\
\hline & Female & & 228 & 37.9 \\
\hline \multirow[t]{2}{*}{ Age } & $<60$ & & 221 & 36.7 \\
\hline & $\geq 60$ & & 381 & 63.3 \\
\hline \multirow[t]{3}{*}{ Marital status } & Single & & 27 & 4.5 \\
\hline & Married & & 522 & 86.7 \\
\hline & Divorced/widowed & & 53 & 8.8 \\
\hline \multirow[t]{2}{*}{ Living arrangement } & Living alone & & 34 & 5.6 \\
\hline & Living with family & & 568 & 94.4 \\
\hline \multirow[t]{3}{*}{ Living environment } & Urban area & & 404 & 67.1 \\
\hline & Town & & 129 & 21.4 \\
\hline & Rural & & 69 & 11.5 \\
\hline \multirow[t]{3}{*}{ Education level } & $\begin{array}{l}\text { Junior high school or less } \\
\text { or less }\end{array}$ & & 231 & 38.4 \\
\hline & High school & & 233 & 38.7 \\
\hline & College or higher & & 138 & 22.9 \\
\hline \multirow[t]{2}{*}{ Employment } & employed & & 146 & 24.3 \\
\hline & unemployed & & 456 & 75.7 \\
\hline \multirow[t]{4}{*}{ Household income per capita } & $\leq 2420$ & & 59 & 9.8 \\
\hline & $2421 \sim 4000$ & & 157 & 26.1 \\
\hline & $4001 \sim 5000$ & & 200 & 33.2 \\
\hline & $\geq 5001$ & & 186 & 30.9 \\
\hline \multirow[t]{2}{*}{ Payment methods } & Public expense & & 535 & 88.9 \\
\hline & At own expense & & 67 & 11.1 \\
\hline \multirow[t]{5}{*}{ Medical diagnoses } & Stroke & & 131 & 21.8 \\
\hline & $C A D$ & & 132 & 21.9 \\
\hline & Cancer & & 145 & 24.1 \\
\hline & COPD & & 88 & 14.6 \\
\hline & Diabetes & & 106 & 17.6 \\
\hline Disease course & & $4.21(6.38)$ & & \\
\hline Length of stay & & $11.55(16.23)$ & & \\
\hline \multirow[t]{3}{*}{ Hospitalization frequency } & First hospitalization & & 236 & 39.2 \\
\hline & Re-hospitalization & & 169 & 28.1 \\
\hline & Multiple hospitalizations & & 197 & 32.7 \\
\hline \multirow[t]{3}{*}{ Knowledge of disease } & Know-nothing & & 49 & 8.1 \\
\hline & Know part of it & & 281 & 46.7 \\
\hline & Master & & 272 & 45.2 \\
\hline \multirow[t]{2}{*}{ Need to take medicine regularly for a long time } & YES & & 513 & 85.2 \\
\hline & NO & & 89 & 14.8 \\
\hline
\end{tabular}

$(P=0.10)$, COPD and diabetes $(P=0.10)$, stroke and cancer $(P=0.41), \mathrm{CHD}$ and cancer $(P=0.10)$.

Table 3 compares the total score of QDTS and the scores of each dimension of patients from different hospitals. The scores of QDTS - Needed were not significantly different between the 7 hospitals. However, we found statistically significant difference among analyzed hospitals according to QDTS - Received, Teaching skills and effectiveness, and the total score of QDTS. 
Table 2 Comparison of the total score and each dimension score of QDTS in discharged patients with different diseases $(n=602)$

\begin{tabular}{llllll}
\hline Item & Frequency(n) & $\begin{array}{l}\text { QDTS - Needed } \\
\text { Mean (SD) }\end{array}$ & $\begin{array}{l}\text { QDTS - Received } \\
\text { Mean (SD) }\end{array}$ & $\begin{array}{l}\text { Teaching skills and effectiveness } \\
\text { Mean (SD) }\end{array}$ & $\begin{array}{l}\text { Total score } \\
\text { Mean (SD) }\end{array}$ \\
\hline Stroke & 131 & $46.59(12.55)$ & $48.69(9.85)$ & $105.76(15.29)$ & $154.46(22.08)$ \\
CHD & 132 & $49.52(11.33)$ & $52.72(9.11)$ & $108.88(16.99)$ & $161.60(24.70)$ \\
Cancer & 145 & $47.48(13.45)$ & $49.56(11.07)$ & $49.56(11.07)$ & $156.75(24.26)$ \\
COPD & 88 & $47.65(14.18)$ & $45.69(11.92)$ & $45.69(11.92)$ & $149.23(23.80)$ \\
Diabetes & 106 & $44.62(12.96)$ & $47.74(11.92)$ & $47.74(10.67)$ & $154.33(19.47)$ \\
$F$ & & 2.234 & 6.834 & 1.821 & 4.159 \\
$P$ & 0.06 & $<0.001$ & 0.12 & 0.002 \\
\hline
\end{tabular}

Abbreviations: CHD coronary heart disease, COPD chronic obstructive pulmonary disease, QDTS quality of discharged teaching scale, SD standard deviation, $p, p$-value

\section{Comparison of content-needed and content-received score of discharged patients with different kinds of diseases (Table 4)}

The results of Table 4 show that there are differences in the demand for guidance content among patients with different diseases. Patients with stroke, CHD and cancer have the highest demand for "medical processing information". COPD patients have the highest demand for "seeking help information". Diabetics have the highest demand for "Family members' informational needs". And the paired t-test showed that except for the two items of " medical information " and "treatment practice" of COPD patients were not satisfied, that is, the score of the content-received was lower than that of the content-needed. There was no statistically significant difference between the scores of other items needed and received.

\section{Patients' evaluation of discharge guidance skills and effectiveness (Table 5)}

The average score of discharge guidance skills and effects are 8.53-9.03. The items with the highest and lowest scores are "Do you like the way nurses guide", and " Can the information provided by the nurse address your concerns and questions ". The scores of other entries are shown in Table 5.

\section{Discussion}

The quality of discharge teaching is in the upper-middle level, and there are differences among different departments

The overall score of chronic disease patients' QDTS in this survey was slightly higher than that reported by Weiss et al. [10]. It shows that the QDTS of chronic disease patients is at a high level, which may be because that the data of this study came from the large tertiary general hospitals, the nurses have higher education background, and the professional training in the hospital was more frequent and strict, so the nurses had higher professional literacy and could guide the patients better. As can be seen from Table 2 that the differences in the total score and the scores of the QDTS - received by different departments are statistically significant $(P<0.01)$. And further pairwise comparison found that the total score of QDTS of COPD was the lowest, which was lower than that of stroke, CHD, cancer, and diabetes. It could be caused by the following reason. COPD was an age-related condition, and several evidences suggested a

Table 3 Comparison of the total score and each dimension score of QDTS in discharged patients with different hospitals $(n=602)$

\begin{tabular}{llllll}
\hline Item & Frequency(n) & $\begin{array}{l}\text { QDTS - Needed } \\
\text { Mean (SD) }\end{array}$ & $\begin{array}{l}\text { QDTS - Received } \\
\text { Mean (SD) }\end{array}$ & $\begin{array}{l}\text { Teaching skills and effectiveness } \\
\text { Mean (SD) }\end{array}$ & $\begin{array}{l}\text { Total score } \\
\text { Mean (SD) }\end{array}$ \\
\hline A Hospital & 122 & $45.30(15.79)$ & $48.45(11.72)$ & $109.20(11.54)$ & $157.65(20.39)$ \\
B Hospital & 83 & $49.08(13.21)$ & $50.16(9.11)$ & $103.19(17.39)$ & $153.35(24.93)$ \\
C Hospital & 85 & $48.06(12.99)$ & $46.95(11.34)$ & $103.68(15.05)$ & $150.64(24.37)$ \\
D Hospital & 98 & $49.52(8.90)$ & $52.01(7.43)$ & $109.61(11.98)$ & $161.62(18.47)$ \\
E Hospital & 78 & $45.14(13.79)$ & $46.59(12.82)$ & $107.19(13.67)$ & $153.78(22.81)$ \\
F Hospital & 56 & $46.16(11.82)$ & $47.43(11.91)$ & $96.55(21.96)$ & $143.98(31.57)$ \\
G Hospital & 80 & $47.53(11.53)$ & $51.91(8.54)$ & $112.13(11.81)$ & $164.04(18.40)$ \\
F & & 1.726 & 3.983 & 9.082 & 6.508 \\
$P$ & 0.11 & 0.001 & 0.000 & 0.000 \\
\hline
\end{tabular}

Abbreviations: QDTS quality of discharged teaching scale, SD standard deviation, $p$ p-value 
Table 4 Comparison of content-needed and content-received score $(n=602)$

\begin{tabular}{|c|c|c|c|c|c|}
\hline \multirow[t]{2}{*}{ Item } & \multirow{2}{*}{$\begin{array}{l}\text { Stroke } \\
(n=131) \\
\text { Mean (SD) }\end{array}$} & \multirow{2}{*}{$\begin{array}{l}\text { CHD } \\
(n=132) \\
\text { Mean (SD) }\end{array}$} & \multirow{2}{*}{$\begin{array}{l}\text { Cancer } \\
(n=145) \\
\text { Mean (SD) }\end{array}$} & \multirow{2}{*}{$\begin{array}{l}\text { COPD } \\
(n=88) \\
\text { Mean (SD) }\end{array}$} & \multirow{2}{*}{$\begin{array}{l}\operatorname{DM}(n=106) \\
\text { Mean (SD) }\end{array}$} \\
\hline & & & & & \\
\hline Information needed about taking care of oneself & $7.64(2.22)$ & $7.87(2.64)$ & $7.82(2.57)$ & $7.89(2.77)$ & $7.27(2.66)$ \\
\hline Information received about taking care of oneself & $8.17(1.83)$ & $8.77(1.84)$ & $8.21(2.06)$ & $7.93(2.14)$ & $8.06(2.03)$ \\
\hline$t$ & -3.351 & -4.314 & -2.091 & -0.240 & -3.250 \\
\hline$P$ & 0.001 & $<0.001$ & 0.04 & 0.81 & 0.002 \\
\hline Emotion regulation information needed & $7.56(2.34)$ & $7.9(2.43)$ & $7.74(2.61)$ & $7.68(2.85)$ & $7.25(2.63)$ \\
\hline Emotion regulation information received & $8.19(1.86)$ & $8.79(1.78)$ & $8.32(1.97)$ & $7.53(2.36)$ & $8.00(1.88)$ \\
\hline$t$ & -3.823 & -4.536 & -3.119 & 0.615 & -3.389 \\
\hline$P$ & $<0.001$ & $<0.001$ & 0.002 & 0.54 & 0.001 \\
\hline Information needed about medical needs and/or treatments & $7.92(2.18)$ & $8.48(2.03)$ & $8.08(2.33)$ & $8.02(2.23)$ & $7.31(2.60)$ \\
\hline Information received about medical needs and/or treatments & $8.02(1.85)$ & $8.81(1.54)$ & $8.33(1.95)$ & $7.56(2.17)$ & $7.95(2.09)$ \\
\hline t & -0.553 & -1.995 & -1.509 & 2.211 & -2.890 \\
\hline$P$ & 0.58 & 0.05 & 0.13 & 0.03 & 0.005 \\
\hline Practice needed with treatments and/or medications & $7.68(2.31)$ & $8.34(2.06)$ & $7.77(2.53)$ & $7.94(2.51)$ & $7.14(2.62)$ \\
\hline Practice received with treatments and/or medications & $7.98(1.99)$ & $8.67(1.82)$ & $8.10(2.11)$ & $7.32(2.34)$ & $7.64(2.30)$ \\
\hline t & -1.879 & -2.355 & -1.853 & 2.856 & -2.252 \\
\hline$P$ & 0.06 & 0.02 & 0.07 & 0.005 & 0.03 \\
\hline Information needed about who and when to call for problems or emergencies & $7.91(2.18)$ & $8.48(1.91)$ & $8.01(2.41)$ & $8.07(2.48)$ & $7.77(2.41)$ \\
\hline $\begin{array}{l}\text { Information received about who and when to call for problems or } \\
\text { emergencies }\end{array}$ & $8.13(1.71)$ & $8.87(1.55)$ & $8.24(2.14)$ & $7.82(2.13)$ & $8.08(1.95)$ \\
\hline$t$ & -1.489 & -2.611 & -1.298 & 1.110 & -1.600 \\
\hline$P$ & 0.14 & 0.01 & 0.20 & 0.27 & 0.11 \\
\hline Family members' informational needs & $7.87(2.32)$ & $8.40(2.15)$ & $8.05(2.33)$ & $8.05(2.42)$ & $7.87(2.46)$ \\
\hline Information received by family members & $8.21(1.72)$ & $8.82(1.54)$ & $8.37(2.10)$ & $7.53(2.45)$ & $8.01(2.10)$ \\
\hline$t$ & -1.850 & -2.516 & -2.064 & 2.272 & -0.614 \\
\hline$P$ & 0.07 & 0.01 & 0.04 & 0.03 & 0.54 \\
\hline Content needed & $\begin{array}{l}46.59 \\
(12.55)\end{array}$ & $\begin{array}{l}49.52 \\
(11.33)\end{array}$ & $\begin{array}{l}47.48 \\
(13.45)\end{array}$ & $\begin{array}{l}47.65 \\
(14.18)\end{array}$ & $\begin{array}{l}44.62 \\
(13.30)\end{array}$ \\
\hline Content received & $48.69(9.85)$ & $52.72(9.11)$ & $\begin{array}{l}49.56 \\
(11.07)\end{array}$ & $\begin{array}{l}45.69 \\
(11.92)\end{array}$ & $\begin{array}{l}47.74 \\
(10.67)\end{array}$ \\
\hline$t$ & -2.772 & 4.168 & 2.513 & 1.867 & 2.911 \\
\hline$P$ & 0.006 & $<0.001$ & 0.01 & 0.07 & 0.004 \\
\hline
\end{tabular}

Abbreviations: CHD coronary heart disease, COPD chronic obstructive pulmonary disease, $D M$ diabetes, $S D$ standard deviation, $t$ t-test pairs, $p$-value

relationship with a rapidly increasing aging [14, 15]. It seems like older patients are more likely to develop subtle cognitive deficits [16]. These deficits are often not recognized by clinicians and may impair understanding $[17,18]$.

In addition, Table 2 also shows that patients with CHD need the highest content dimension score, suggesting that even at higher levels of patient demand, the discharge guidance provided by the nurse can still meet the patient's needs. It is recommended that the nursing manager further study the characteristics of the nurses and ward in each department. For departments whose guidance quality needs to be improved, managers should enhance their nurses' understanding of discharge guidance, encourage them to learn from the experience of excellent departments, and guide and help the nurses actively explore the characteristics of patients and possible out-of-hospital needs, and constantly improve the quality of care. Recommendations for improving discharge teaching emphasize a patient and familycentered approach, in which content and teaching method should be tailored to patient/family characteristics and circumstances, rather than the typical approach of patient diagnosis with standardized information [19]. 
Table 5 Scores of patients on the evaluation of teaching skills and effectiveness $(\bar{x} \pm s)$

\begin{tabular}{lc}
\hline Item & Average score of each item \\
\hline Do you like the way nurses guide? & $9.03 \pm 1.38$ \\
Do you get the same information from nurses, doctors, and other health workers? & $9.02 \pm 1.38$ \\
Can you understand the way the nurse instructs you to take care of yourself? & $9.02 \pm 1.39$ \\
Is it the right time for the nurse to provide you with self-care information? & $8.96 \pm 1.41$ \\
Does the nurse respect your religious beliefs or values? & $8.95 \pm 1.67$ \\
Will the nurse choose the time when your family or other caregivers can be present to provide you with information? & $8.95 \pm 1.49$ \\
Can nurses help you improve your confidence in your ability to take care of yourself at home? & $8.94 \pm 1.55$ \\
Can nurses listen to your concerns? & $8.93 \pm 1.53$ \\
Will the nurse check to make sure you understand the information she provides or masters her demonstration? & $8.86 \pm 1.67$ \\
Can the self-care information provided by nurses reduce your anxiety about returning home? & $8.79 \pm 1.74$ \\
How confident are you that you know what to do in an emergency? & $8.65 \pm 1.65$ \\
Can the information provided by the nurse address your concerns and questions? & $8.53 \pm 1.78$
\end{tabular}

The needs of discharge guidance for patients with different kinds of diseases can be met

The differences in the demand for guidance content among patients with different diseases may be related to the patient group and treatment characteristics of the department. After treatment, there may be surgical incision dressing change, rehabilitation and other medical treatment in patients with stroke, CHD, and cancer. Patients with COPD who encounter problems in acute exacerbation are more likely to seek medical help directly. The treatment of patients with diabetes needs to change their previous lifestyle and eating habits and persist in taking medicine, which requires the cooperation and help of their caregivers. It is suggested that the content of discharge guidance provided to patients should be emphasized according to the disease characteristics of the department.

\section{Chronic disease patients have a high evaluation of discharge guidance skills and effects, but there is still room for improvement}

The average score of discharge guidance skills and effects are 8.53-9.03, indicating that chronic disease patients have a high evaluation of nurses' guidance skills. However, the effect of discharge guidance still needs to be improved. Patients have the lowest score on " Can the information provided by the nurse address your concerns and questions ". We suspect that the following factors contributed. First, inadequate coordination within multidisciplinary discharge teams. Both physicians and nurses overestimate patients' knowledge, which may make them less likely to provide sufficient education [20, 21]. Second, lack of feedback. Patients may have difficulty in understanding these instructions. A study on quality of discharge practices and patient understanding found that among the patients who felt very familiar with the discharge guidance, $40 \%$ could not accurately describe the reason for hospitalization, and 54\% were unable to recall the instructions for the scheduled follow-up [22]. Third, lack of standardization in discharge procedures. Although guidelines for discharge care currently endorsed by the National Quality Forum [23] and others $[24,25]$ provide excellent templates, research has shown that the implementation of these standards at the hospital and physician level is limited [26].

Therefore, it is the key to exploring the methods to improve discharge practices. A safe and patient-centered passage from the hospital should therefore include highquality provision of discharge instruction [27]. For example, leaflets or brochures should be provided to the patients at discharge, including guidance and educational materials appropriate to the patient's language and education level. Emphasis should be on the use of simple terms and shorter sentences [28]. In addition, these documents should focus on conveying key messages to patients, and focus on the information that patients need to know for self-management after discharge. Both written and oral discharge information should be communicated to the patient / family caregiver, focusing on assessment and ensuring that they understand the discharge information. Another method to improve comprehension is using a "teach-back" technique, which has been widely advocated as a teaching method to improve patient understanding of discharge instructions [29, 30]. So that health care providers can verify the patients have understood the information or correct misperceptions [31]. It is also suggested that discharge guidance should be divided into stages and health guidance should be integrated into daily nursing work. Besides, in the process of discharge guidance, attention should be paid to detailed guidance, so that patients can acquire more clear and understandable knowledge, reduce anxiety, and promote their competence in-home care. However, education alone cannot improve the quality of teaching. 
Leadership support to monitor discharge teaching quality, modify clinical care delivery systems as needed, and assess staffing patterns is critical to addressing this important but often overlooked aspect of care. Highlighting improved quality of pre-discharge teaching will support the strategic efforts of hospitals and caregivers to improve discharge care and outcomes [32].

\section{Limitations and recommendations}

A limitation of this study was that all of the subjects in this study were from tertiary hospitals. Accordingly, the results of this study may not be applicable to other populations. Subsequent studies can be conducted in different regions and different capacities to further understand the quality of discharge guidance for patients with chronic diseases. Also focusing on interventions to improve patient empowerment will be important in the future.

\section{Conclusion}

The results of this survey suggest that there are differences in the quality of discharge guidance in different departments, and the needs of patients with different kinds of diseases are different. Therefore, it is suggested that nursing managers should understand the characteristics of various departments, give corresponding guidance and help, and clinical nurses should understand the characteristics of ward patients and pay more attention to individual guidance. At the same time, we should actively explore how to provide more comprehensive and effective education in a short and limited time, further improve the quality of discharge guidance, and help patients meet the health challenges after discharge.

\section{Supplementary information}

Supplementary information accompanies this paper at https://doi.org/10. 1186/s12913-020-05518-6.

Additional file 1. Demographic questionnaire

\section{Abbreviations}

ANOVA: Analysis of Variance; COPD: Chronic Obstructive Pulmonary Disease; CHD: Coronary Heart Disease; DM: Diabetes; QDTS: Quality of Discharged Teaching Scale; I-CVI: Item-Content validity index; S-CVI: Scale-Content validity index; SD: Standard Deviation

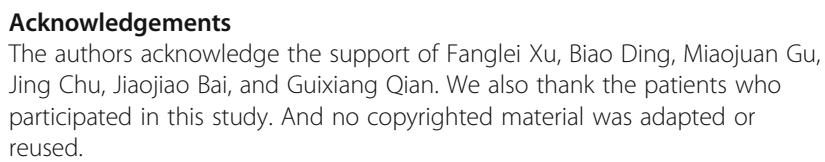

\section{Authors' contributions}

YMM, ZHH and LW conceived and designed the study; LW and ZY performed the study; YMM analyzed the data and wrote the manuscript; ZY contributed to discussion, editing of the interpretation. YMM and ZHH revised the manuscript. All authors have read and approved the manuscript.

\section{Funding}

This work was supported by Shanghai Municipal Population and Family Planning Commission [grant number 201840116]. The funders had no role in study design, data collection and analysis, decision to publish, or preparation of the manuscript.

\section{Availability of data and materials}

The datasets used and/or analysed during the current study are available from the corresponding author on reasonable request.

\section{Ethics approval and consent to participate}

The study was approved by Ethics Committee of Zhongshan Hospital Fudan University(B2018-202R). Written Informed consent was obtained from all the patients.

Consent for publication

Not applicable.

\section{Competing interests}

The authors declare that they have no competing interests.

Received: 18 April 2020 Accepted: 7 July 2020

Published online: 11 July 2020

References

1. McAlearney AS, Sieck CJ, Hefner JL, Aldrich AM, Walker DM, Rizer MK, Moffatt-Bruce SD, Huerta TR. High touch and high tech (HT2) proposal: transforming patient engagement throughout the continuum of care by engaging patients with portal Technology at the Bedside. JMIR Res Protoc. 2016:5(4):e221.

2. Clarke SF, Foster JR. A history of blood glucose meters and their role in selfmonitoring of diabetes mellitus. Br J Biomed Sci. 2012;69(2):83-93.

3. Krist AH, Woolf SH, Rothemich SF, Johnson RE, Peele JE, Cunningham TD, Longo DR, Bello GA, Matzke GR. Interactive preventive health record to enhance delivery of recommended care: a randomized trial. Ann Fam Med. 2012;10(4):312-9.

4. Osborn CY, Mayberry LS, Mulvaney SA, Hess R. Patient web portals to improve diabetes outcomes: a systematic review. Curr Diab Rep. 2010;10(6): 422-35

5. Wong EL, Coulter A, Cheung AW, Yam CH, Yeoh EK, Griffiths SM. Patient experiences with public hospital care: first benchmark survey in Hong Kong. Hong Kong Med J. 2012;18(5):371-80.

6. Forster AJ, Clark HD, Menard A, Dupuis N, Chernish R, Chandok N, Khan A, van Walraven C. Adverse events among medical patients after discharge from hospital. Cmaj. 2004;170(3):345-9.

7. Krohn DA. Discharge instructions in the outpatient setting: nursing considerations. J Radiol Nurs. 2008;27(1):29-33.

8. Mitchell JP. Association of provider communication and discharge instructions on lower readmissions. J Healthc Qual. 2015;37(1):33-40.

9. Ashbrook L, Mourad M, Sehgal N. Communicating discharge instructions to patients: a survey of nurse, intern, and hospitalist practices. J Hosp Med. 2013:8(1):36-41.

10. Weiss ME, Piacentine LB, Lokken L, Ancona J, Archer J, Gresser S, Holmes SB, Toman S, Toy A, Vega-Stromberg T. Perceived readiness for hospital discharge in adult medical-surgical patients. Clin Nurse Spec. 2007;21(1):3142.

11. Knier S, Stichler JF, Ferber L, Catterall K. Patients' perceptions of the quality of discharge teaching and readiness for discharge. Rehabil Nurs. 2015;40(1): $30-9$

12. Qiu C, Feng X, Zeng J, Luo H, Lai Z. Discharge teaching, readiness for discharge, and post-discharge outcomes in cataract patients treated with day surgery: a cross-sectional study. Indian J Ophthalmol. 2019;67(5):612-7.

13. Wang $B H$, Wang $H$, Yang $C$. Reliability and validity of the Chinese version of the quality of discharge teaching scale. Chin J Nurs. 2016;51(06):752-5.

14. Feenstra TL, van Genugten ML, Hoogenveen RT, Wouters EF, Rutten-van Mölken MP. The impact of aging and smoking on the future burden of chronic obstructive pulmonary disease: a model analysis in the Netherlands. Am J Respir Crit Care Med. 2001;164(4):590-6.

15. Kim EJ, Yoon SJ, Kim YE, Go DS, Jung Y. Effects of aging and smoking duration on cigarette smoke-induced COPD severity. J Korean Med Sci. 2019;34(Suppl 1):e90. 
16. Krumholz HM. Post-hospital syndrome--an acquired, transient condition of generalized risk. N Engl J Med. 2013;368(2):100-2.

17. Torisson G, Minthon L, Stavenow L, Londos E. Cognitive impairment is undetected in medical inpatients: a study of mortality and recognition amongst healthcare professionals. BMC Geriatr. 2012;12:47.

18. Chodosh J, Petitti DB, Elliott M, Hays RD, Crooks VC, Reuben DB, Galen Buckwalter J, Wenger N. Physician recognition of cognitive impairment: evaluating the need for improvement. J Am Geriatr Soc. 2004;52(7):1051-9.

19. Care Transitions From Hospital to Home: IDEAL Discharge Planning [http:// www.ahrq.gov/professionals/systems/hospital/engagingfamilies/strategy4/ index.html]. Accessed 14 Feb 2020.

20. Reiley P, lezzoni LI, Phillips R, Davis RB, Tuchin LI, Calkins D. Discharge planning: comparison of patients and nurses' perceptions of patients following hospital discharge. Image J Nurs Sch. 1996;28(2):143-7.

21. Calkins DR, Davis RB, Reiley P, Phillips RS, Pineo KL, Delbanco TL, lezzoni LI. Patient-physician communication at hospital discharge and patients' understanding of the postdischarge treatment plan. Arch Intern Med. 1997; 157(9):1026-30.

22. Horwitz LI, Moriarty JP, Chen C, Fogerty RL, Brewster UC, Kanade S, Ziaeian B, Jenq GY, Krumholz HM. Quality of discharge practices and patient understanding at an academic medical center. JAMA Intern Med. 2013; 173(18):1715-22.

23. Clancy CM. Reengineering hospital discharge: a protocol to improve patient safety, reduce costs, and boost patient satisfaction. Am J Med Qual. 2009; 24(4):344-6.

24. Snow V, Beck D, Budnitz T, Miller DC, Potter J, Wears RL, Weiss KB, Williams MV. Transitions of care consensus policy statement American College of Physicians-Society of general internal medicine-Society of Hospital Medicine-American Geriatrics Society-American College of emergency physicians-Society of Academic Emergency Medicine. J Gen Intern Med. 2009;24(8):971-6.

25. Coleman EA, Mahoney E, Parry C. Assessing the quality of preparation for posthospital care from the patient's perspective: the care transitions measure. Med Care. 2005;43(3):246-55.

26. Greysen SR, Schiliro D, Horwitz LI, Curry L, Bradley EH. "Out of sight, out of mind": housestaff perceptions of quality-limiting factors in discharge care at teaching hospitals. J Hosp Med. 2012;7(5):376-81.

27. O'Leary KJ, Liebovitz DM, Feinglass J, Liss DT, Evans DB, Kulkarni N, Landler MP, Baker DW. Creating a better discharge summary: improvement in quality and timeliness using an electronic discharge summary. J Hosp Med. 2009;4(4):219-25.

28. Choudhry AJ, Baghdadi YM, Wagie AE, Habermann EB, Heller SF, Jenkins DH, Cullinane DC, Zielinski MD. Readability of discharge summaries: with what level of information are we dismissing our patients? Am J Surg. 2016; 211(3):631-6.

29. Health literacy universal precautionstoolkit, 2nd ed.: Use the Teach-Back method [https:/www.ahrq.gov/health-literacy/quality-resources/tools/ literacy-toolkit/healthlittoolkit2-tool5.html]. Accessed 14 Feb 2020.

30. Kornburger C, Gibson C, Sadowski S, Maletta K, Klingbeil C. Using "teachback" to promote a safe transition from hospital to home: an evidencebased approach to improving the discharge process. J Pediatr Nurs. 2013; 28(3):282-91.

31. Schillinger D, Piette J, Grumbach K, Wang F, Wilson C, Daher C, Leong-Grotz K, Castro C, Bindman AB. Closing the loop: physician communication with diabetic patients who have low health literacy. Arch Intern Med. 2003; 163(1):83-90.

32. Weiss ME, Sawin KJ, Gralton K, Johnson N, Klingbeil C, Lerret S, Malin S, Yakusheva O, Schiffman R. Discharge teaching, readiness for discharge, and post-discharge outcomes in parents of hospitalized children. J Pediatr Nurs. 2017;34:58-64.

\section{Publisher's Note}

Springer Nature remains neutral with regard to jurisdictional claims in published maps and institutional affiliations.

\section{Ready to submit your research? Choose BMC and benefit from:}

- fast, convenient online submission

- thorough peer review by experienced researchers in your field

- rapid publication on acceptance

- support for research data, including large and complex data types

- gold Open Access which fosters wider collaboration and increased citations

- maximum visibility for your research: over $100 \mathrm{M}$ website views per year

At BMC, research is always in progress.

Learn more biomedcentral.com/submissions 